\title{
Studying Tumor Initiating Cell (TIC) Heterogeneity and Treatment Resistance by Single-Cell Microfluidics Technology
}

\section{Lidong Qin*}

Department of Nanomedicine, The Methodist Hospital Research Institute, Houston, TX 77030, USA

In 2003, Clarke and colleagues used limiting dilution transplantation of $\mathrm{CD} 44^{+} / \mathrm{CD} 24$ cells into the mammary fat pad of immunecompromised nonobese diabetic/severe-combined immunodeficiency (NOD-SCID) mice and provided the first evidence of a Tumor Initiating Cell (TIC) subpopulation from breast cancer pleural effusions [1]. Recent investigations from both animal models and clinical samples have continuously supported that TIC does exist and plays an important role in tumor metastasis and recurrence [1,2]. However, TICs have a few intrinsic properties leading to their complexity in molecular targeting and inhibition. TICs are 1) heterogeneous [3-7], 2) dynamically changing states $[8,9], 3)$ often rare $[1,10]$ and 4) lack robust biomarker combinations [4], thereby challenging conventional bulk in vitro experimental tools and complicating the prediction and explanation of animal study results. High throughput, in situ, and cellby-cell measurement on TICs is a way to fully decipher TIC's molecular signature and signaling pathways. We believe such measurement can lead to 1) revolutionary implementation of TIC models; 2) identification of new therapeutic targets; and 3) reduction of breast cancer recurrence and metastasis. Microfluidics technology is a candidate to serve as such type of high throughput single-cell characterization.

We started pursuing such measurements a few years ago and demonstrated high throughput single-cell protein profiling on both cell lines and clinical samples [11-15]. The technology, called singlecell barcode chip (SCBC) [11,12], is facilitated by state-of-the-art Polydimethylsiloxane (PDMS) microfluidics protocols. The SCBC consists of down to nanoliter chambers that concentrate proteins from individual cells to a level even higher than cell culture media in conventional dish technology and contains extremely miniaturized antibody arrays to capture proteins produced by cells in these chambers. Further utilization of our SCBC platform to TICs is expected to characterize protein expression from individual breast TIC and lead to new discoveries in TIC filed.

As shown in Figure 1, by applying enriched TIC candidate cells to SCBC and on chip culturing, SCBC will be able to measure proteins produced from individual cells over a panel of functions including self-renewal capability, mammosphere forming capability, and others. Study of individual TIC response to targeted inhibitors may lead to new investigation in the hidden mechanisms involved in the TIC drug resistance. The focus could be on chip single-cell study on the expression of proteins with functions of apoptosis, disease progression and tumor malignancy from each individual cell under in situ drug treatments (Figure 2).

Tumor recurrence drug screening is another advantage of using single cell microfluidics technology. Particularly, studying the metastatic mechanism by the in vitro microfluidics model systems may lead to new drug targets that particularly inhibit TIC. Figure 2 represents a schematic design of a single cell technology to mimic the tumor recurrence microenvironment. The Metastatic Assessment Chip (MAC) integrates functions including engineered tissue pads containing matrigel and stroma cells, cell loading/culturing and drug testing chambers, migration and invasion channel, and antibody arrays, to study tumorigenic process from individual TICs.
In the MAC design, we first load matrigel and breast stroma cells (fibroblast, immune cells, healthy breast epithelial/endothelial cells, fat cells, and/or others) and culture the mixture till an engineered tissue graft is formed. We then load the other side of the MAC device with cancer cells and test drugs and observe the cells migrating and invading into the artificial tissue pad. The device will be able to handle thousands of tests on one glass slide size chip. Antibody arrays will also be printed under the cell culture chamber so that the cancer cell migration capability could be correlated to protein production. We expect MAC could serve as the artificial tissue graft that mimics tumor metastasis and provides a platform to study the relationship between molecular signature and tumor spreading behavior at single cell level.

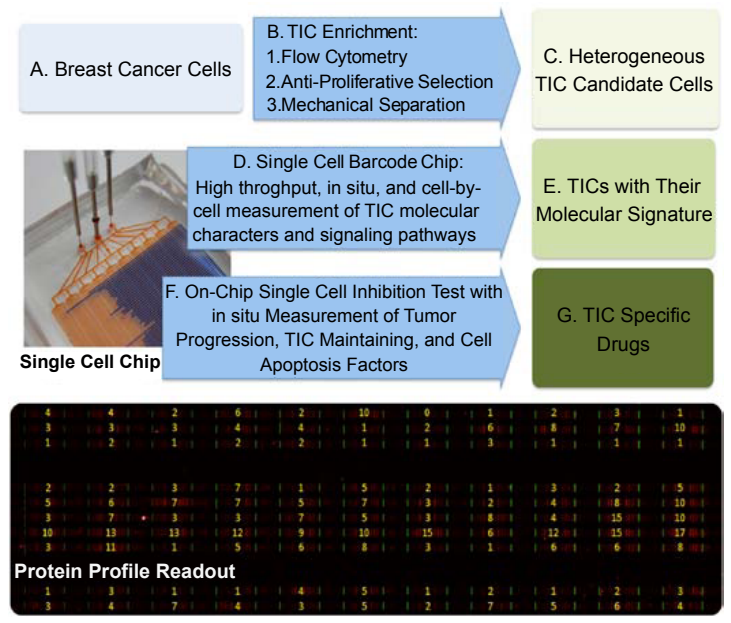

Figure 1: A single cell strategy to study TIC heterogeneity and perform TIC specific inhibitor selection. Text boxes A-F present the flow chart of our study. TIC candidate cells are enriched from patient-derived human breast tumor xenografts and applied to SCBC for cell-by-cell protein expression study. The TIC proteome is then analyzed in SCBC and potential signaling pathways are summarized from high throughput single cell data. These pathways are next inhibited by on-chip single cell treatment test. With in situ TIC function test, TIC specific drugs are identified and subjected to next step animal validation. Shown on the left is a typical SCBC device for single cell proteome measurements and shown on the bottom is our preliminary cancer cell secretome data. In the bottom image, yellow numbers are cells $(0,1$, to a few) trapped in nanoliter chambers, where the barcodes represent intensities of secreted proteins from the cells.

*Corresponding author: Lidong Qin, Department of Nanomedicine, The Methodist Hospital Research Institute, Houston, TX 77030, USA, E-mail: Iqin@tmhs.org

Received August 13, 2012; Accepted August 16, 2012; Published August 18 , 2012

Citation: Qin L (2012) Studying Tumor Initiating Cell (TIC) Heterogeneity and Treatment Resistance by Single-Cell Microfluidics Technology. Single Cell Biol 1:e112. doi: 10.4172/2168-9431.1000e112

Copyright: () 2012 Qin L. This is an open-access article distributed under the terms of the Creative Commons Attribution License, which permits unrestricted use, distribution, and reproduction in any medium, provided the original author and source are credited. 
Citation: Qin L (2012) Studying Tumor Initiating Cell (TIC) Heterogeneity and Treatment Resistance by Single-Cell Microfluidics Technology. Single Cell Biol 1:e112. doi: 10.4172/2168-9431.1000e112

Page 2 of 2

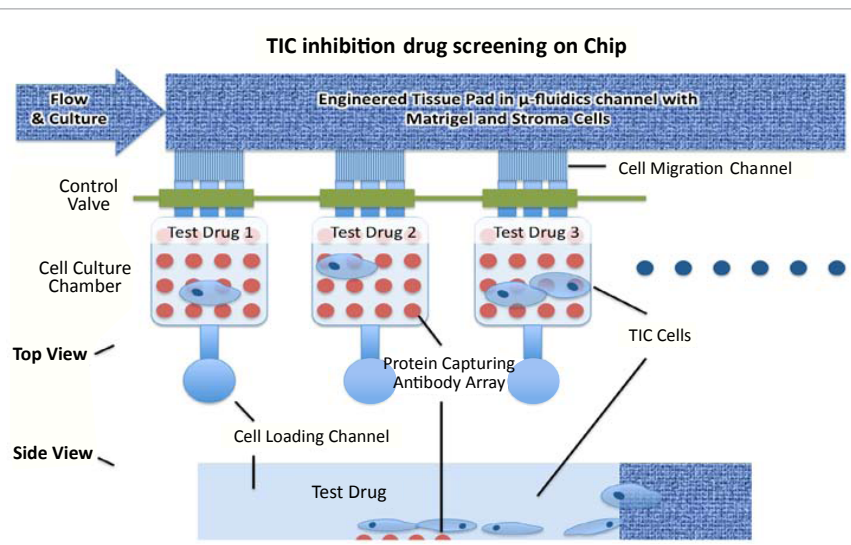

Figure 2: Design of Metastasis Assessing Chip (MAC) for rapid anti-TIC drug tests. The design contains engineered tissue pad made of Matrigel and stroma cells. It also contains cancer cell culture, drug test, and secreted protein expression test.

Overall, the significance of single cell technology to study TIC includes that 1) success of single cell protein measurements on TICs can identify new drug targets to eliminate TIC; 2 ) investigation of both secreted proteins and lysate proteins at individual cell level could lead to signaling mechanisms of TIC renewal and proliferation, which will inspire not only breast cancer research, but also other types of recurring cancer; and 3) screening drugs at single cell level could help identify drug efficacy on true TIC and avoid confusing results from non-TIC neighboring cells.

\section{Acknowledgement}

Supported by Cancer Prevention and Research Institute of Texas-R1007.

\section{References}

1. Al-Hajj M, Wicha MS, Benito-Hernandez A, Morrison SJ, Clarke MF (2003) Prospective identification of tumorigenic breast cancer cells. Proc Natl Acad Sci USA 100: 3983-3988.

2. Al-Hajj M, Clarke MF (2004) Self-renewal and solid tumor stem cells. Oncogene 23: $7274-7282$
3. Shipitsin M, Campbell LL, Argani P, Weremowicz S, Bloushtain-Qimron N et al. (2007) Molecular definition of breast tumor heterogeneity. Cancer cell 11: 259-273.

4. Stingl J, Caldas C (2007) Molecular heterogeneity of breast carcinomas and the cancer stem cell hypothesis. Nat Rev Cancer 7: 791-799.

5. Shackleton M, Quintana E, Fearon ER, Morrison SJ (2009) Heterogeneity in Cancer: Cancer Stem Cells versus Clonal Evolution. Cell 138: 822-829.

6. Pece S, Tosoni D, Confalonieri S, Mazzarol G, Vecchi M et al. (2010) Biological and Molecular Heterogeneity of Breast Cancers Correlates with Their Cancer Stem Cell Content. Cell 140: 62-73.

7. Zhou BB, Zhang H, Damelin M, Geles KG, Grindley JC, et al. (2009) Tumourinitiating cells: challenges and opportunities for anticancer drug discovery. Nat Rev Drug Discov 8: 806-823.

8. Scheel C, Eaton EN, Li SH, Chaffer CL, Reinhardt F, et al. (2011) Paracrine and Autocrine Signals Induce and Maintain Mesenchymal and Stem Cell States in the Breast. Cell 145: 926-940.

9. Polyak K, Weinberg RA (2009) Transitions between epithelial and mesenchymal states: acquisition of malignant and stem cell traits. Nat Rev Cancer 9: 265-273.

10. Creighton CJ, Li X, Landis M, Dixon JM, Neumeister VM, et al. (2009) Residual breast cancers after conventional therapy display mesenchymal as well as tumor-initiating features. Proc Natl Acad Sci USA 106: 13820-13825.

11. Ahmad H, Sutherland A, Shin YS, Hwang K, Qin L, et al. (2011) A robotics platform for automated batch fabrication of high density, microfluidics-based DNA microarrays, with applications to single cell, multiplex assays of secreted proteins. Rev Sci Instrum 82: 094301.

12. Shi Q, Qin L, Wei W, Geng F, Fan R, et al. (2012) Single-cell proteomic chip for profiling intracellular signaling pathways in single tumor cells. Proc Natl Acad Sci USA 109: 419-424.

13. Fan R, Vermesh O, Srivastava A, Yen BK, Qin L, et al. (2008) Integrated barcode chips for rapid, multiplexed analysis of proteins in microliter quantities of blood. Nat Biotechnol 26: 1373-1378.

14. Ma C, Fan R, Ahmad H, Shi Q, Comin-Anduix B, et al. (2011) A clinical microchip for evaluation of single immune cells reveals high functional heterogeneity in phenotypically similar T cells. Nat Med 17: 738-743.

15. Qin L, Vermesh O, Shi Q, Heath JR (2009) Self-powered microfluidic chips for multiplexed protein assays from whole blood. Lab Chip 9: 2016-2020. 